\title{
To Find out the Toxicity of Insecticides, Bio-Pesticides and Plant Product against Helicoverpa armigera (Hubner) under Laboratory Conditions
}

\author{
Vipen Kumar*, K.C. Gupta and R.K. Bagri \\ AICRP on Chickpea, Rajasthan Agricultural Research Institute, \\ Durgapura (Jaipur), India \\ *Corresponding author
}

\author{
A B S T R A C T
}

\section{Keywords}

Helicoverpa armigera, Toxicity, Gram pod borer, Bioassay

Article Info

Accepted:

20 December 2018 Available Online: 10 January 2019
The laboratory experiment was conducted at RARI, Durgapura during rabi 2017 to find out the toxicity of insecticides, bio-pesticides \& plant product against $H$. armigera were reared on gram leaves and pods as well as on artificial diets. The nucleus culture of $H$. armigera was maintained in the laboratory under controlled conditions $\left(26+{ }^{\circ} \mathrm{C}\right.$ and 80 +- 5 percent $\mathrm{RH}$ ). The 12 days old larvae of $\mathrm{H}$. armigera use as a test insect by residue film method for bioassay. Various concentration of treatments were prepare and mortality data obtained were corrected using Abbot's formula (Abbott's 1925) The treatments were divided into three categories viz., insecticides, bio- pesticides and plant products. The result shows that, the $\mathrm{LC}_{50}$ value of Quinalphos was $(0.054005 \%)$ shows its superiority over the acephate with LC ${ }_{50}$ of 0.227715 per cent against $H$. armigera. Among the biopesticides the LC 50 value of spinosad (1.0256087\%) which was lower than the b.t.k. $(3.86555 \%)$ and diflubenzuron $(5.37584 \%)$, so it was most effective as compared to other bio-pesticides. Among various plant products the $\mathrm{LC}_{50}$ value of neem oil (1.5738827\%) and eucalyptus oil $(3.2800034 \%)$ thus; neem oil shows its superiority over other plant products. So order of toxicity of different insecticides, bio-pesticides and plant products as under: Insecticides: Quinalphos > Acephate, Bio-pesticides: Spinosad > B.t.k. > Difiubnzuron, Plant product: Neem oil > Karanj oil > Mahua oil > Eucalyptus oil.

\section{Introduction}

Chickpea (Cicer arietinum) is one of the most important pulse crops of India. This is widely cultivated Rabi crop in India and Rajasthan. Among the biotic constraints in its production, the losses caused by insect the pod borer, Helicoverpa armigera (Hubner) is the main constraint during the flowering and pod stage. The yield loss in chickpea due to pod borer was $10-60 \%$ and it is 50 per cent under favourable weather conditions (Bhatt and Patel, 2001). Due to ease of availability and ease of application farmer respond to chemical method for controlling the insect pest to reduce pod borer infestation. However, The use of conventional insecticides causes sudden decrease in natural enemies also. Frequent and high doses of insecticides posed the problems of resistance and resurgence of the pest. Keeping these in view, the present study was undertaken to study the effectiveness of eco- 
safe and to test the relative efficacy of some insecticides, bio-pesticides and botanical with conventional insecticides under laboratory conditions.

\section{Materials and Methods}

The laboratory experiment was conducted at RARI, Durgapura during rabi 2017 with the object of finding out the toxicity of insecticides, bio-pesticides and plant products against $H$. armigera. The nucleus culture of $H$. armigera was maintained in the laboratory under controlled condition $\left(26 \pm 2^{\circ} \mathrm{C}\right.$ and $80 \pm$ 5 percent $\mathrm{RH}$ ) from one to three pairs of $H$. armigera moths which were collected from light trap during night. Adults of $H$. armigera (male and female) were confined in matting cages $\left(50 \times 25 \times 25 \mathrm{~cm}^{3}\right)$. Cotton plug dipped in $10 \%$ sucrose solution was provided in the cage. After copulation, the gravid female was transferred to glass jar lined with blotting paper. A cotton wool plug soaked with $10 \%$ sucrose solution was also placed. The glass jar was kept in a tray filled with water to save them from ant, spider etc. Eggs laid on the blotting paper were collected date wise and kept in jar and plastic container for hatching. The newly hatched larvae were transferred with a camel hair brush to new set of plastic container $(6 \mathrm{~cm} \times 6 \mathrm{~cm})$ having leaves and pods of gram. The larvae were transferred to cleaned new containers every day and used containers were washed with detergent and sterilized by rinsing with 1 percent formaldehyde solution. The larvae attaining pupal stage were transferred date wise to enamel trays containing $4 \mathrm{~cm}$ thick layer of moist sand soil. The trays were examined after 5 days to collect the pupae. The normal healthy pupae collected from the trays were kept date wise in sterilize battery jars. The mouth of the jars was covered with muslin cloth and tightened with rubber bands. The adults so emerged were kept in separate jars in the same manner for mass multiplication up to five generation.
Mass rearing of $H$. armigera on semi synthetic diet

The larvae of $h$. armigera were reared to find out toxicity of insecticides, bio-pesticides and plant product. Rearing was carried out on gram leaves and pods as well as on the artificial diet. The diet formulation use is as per the Anonymous (1995) for rearing the culture. The ingredients used for preparation of semi-synthetic diet have been presented in the table 1 .

\section{Diet preparation procedure}

Water $(390 \mathrm{ml})$ was mixed with fraction A of the diet in the blender which was run for two minutes. Fraction $\mathrm{B}$ was boiled in the remaining $390 \mathrm{ml}$ water. Fraction " $\mathrm{A}$ " and B were mixed and blender is run again for 1 minute. Finally, fraction $\mathrm{C}$ was added to the mixture of $\mathrm{A}$ and $\mathrm{B}$ in water and the blender run again for 1 minute. Formaldehyde solution was added in the end. The diet was poured as per requirement either on the nylon mesh for rearing up to 5-7 days old larvae or in tray cells for rearing the larvae above 5-8 days or poured into sterilized petri plates and allowed to solidify. The diet so prepared could be stored in the refrigerators up to 2 weeks.

\section{Mass rearing procedure on semi-synthetic diet}

For starting culture on artificial diet, newly hatched larvae were transferred from laboratory culture. Initially, they were transferred to a wide mouth glass jar containing fresh gram leaves and pods. Mouth of jars was covered with a piece of transparent plastic sheet perforated finely with pins. The jar was covered with black cloth to allow larvae to settle on the leaf/pods. Next day fresh pods were placed below the older ones. Most of the larvae developed into third instar within six days. The third instar larvae were 
transferred to the cage containing plastic dishes with the artificial diet and then covered by black cloth, the larvae approached the food through the wire screen support and fed from below. The excrement dropped through the screen. Regular cleaning was carried out and fresh supply of food served as and when needed. The fully mature larvae entered the soil for pupation. The soil was sieved to separate pupation carefully.

\section{Laboratory evaluation}

For this purpose various insecticides (Quinalphos, acephate), biopesticides (Bacillus thuringiensis var. Kurstakii (B.t.k), spinosad and diflubenzuron (dimlin) and plant products (neem oil, karanj oil, mahua oil, eucalyptus oil) were taken.

\section{Bioassay technique}

The bioassay was carried out using 12 days old larvae of $H$. armigera as a test insect by residue film method. Various concentration of above treatments was prepared in distilled water and a thin film was prepared on the upper and lower surface of the petriplate. Then the 12 day old larvae of $H$. armigera were released for 24 hours. After 24 hours the mortality was noted. The moribund larvae were also considered as dead. Control was also run simultaneously. The mortality data so obtained were corrected using Abbot's formula (Abbott's, 1925)

$$
\mathrm{P}=\frac{\mathrm{T}-\mathrm{C}}{100-\mathrm{C}}
$$

Where, $\mathrm{P}=$ Corrected per cent mortality

$\mathrm{T}=$ Observed per cent mortality in treatment

$\mathrm{C}=$ per cent mortality in control

The corrected per cent mortality data thus obtained from different concentration of each treatment was subjected to Probit analysis (Finney, 1971) for computing $\mathrm{LC}_{50}$.

\section{Results and Discussion}

The toxicity of different insecticides, biopesticides and plant products against larvae of Helicoverpa armigera (Hubner) under laboratory conditions. The treatments were divided into three categories viz., insecticides, bio-pesticides and plant products.

Table.1 composition of semi-synthetic diet for rearing the larvae of H. armigera

\begin{tabular}{|l|l|l|}
\hline & Item/Ingredients & Quantity \\
\hline A & Chickpea (kabuli gram)flour & $105 \mathrm{~g}$ \\
\hline A & Methyl para-hydroxybenzoate & $2 \mathrm{~g}$ \\
\hline A & Sorbic acid & $1 \mathrm{~g}$ \\
\hline A & Streptomycin sulphate & $0.25 \mathrm{~g}$ \\
\hline A & $10 \%$ formaldehyde solution & $2 \mathrm{ml}$ \\
\hline B & Agar-agar & 12.75 \\
\hline C & Yeast tablets & 25 (Tablets) \\
\hline C & Ascorbic acid & $3.25 \mathrm{~g}$ \\
\hline C & Multivitaplex & 2 capsules \\
\hline C & Vitamin E & $2 \mathrm{~g}$ \\
\hline C & Distilled water & $780 \mathrm{ml}$ \\
\hline C & Miscellaneous & --- \\
\hline
\end{tabular}


Table.2 Relative toxicity of different insecticides, bio-pesticides and plant products against third instar (12 days old) larvae of $H$. armigera

\begin{tabular}{|c|c|c|c|c|c|c|}
\hline Treatment & Heterogeneity & Regression equation & $\mathbf{L C}_{50}(\%)$ & Fiducial limit & Relative toxicity & Remark \\
\hline \multicolumn{6}{|l|}{ Insecticides } & \multirow{3}{*}{ Within insecticides } \\
\hline Quinalphos & 2.5141 & $Y=2.0358 X+-2.598$ & 0.054005 & $\begin{array}{l}0.06572 \\
0.04437\end{array}$ & 4.21 & \\
\hline Acephate & 5.5996 & $Y=2.0061 X+-3.741$ & 0.227715 & $\begin{array}{l}0.28288 \\
0.18330\end{array}$ & 1.00 & \\
\hline \multicolumn{6}{|l|}{ Biopesticides } & \multirow{4}{*}{ Within bio-pesticides } \\
\hline Spinosad & 2.1917927 & $Y=0.9962 X+0.008$ & 1.025608 & $\begin{array}{l}1.51018 \\
0.69652\end{array}$ & 5.24 & \\
\hline Bt (HALT) & 3.7633203 & $Y=3.5208 X+-14.672$ & 3.865553 & $\begin{array}{l}4.34655 \\
3.43778\end{array}$ & 1.39 & \\
\hline $\begin{array}{l}\text { Diflubenzuron } \\
\text { (Dimlin) }\end{array}$ & 0.7228064 & $Y=1.4840 X+-3.504$ & 5.375841 & $\begin{array}{l}8.21406 \\
3.51831\end{array}$ & 1.00 & \\
\hline \multicolumn{6}{|l|}{ Plant products } & \multirow{5}{*}{ Within plant product } \\
\hline Neem oil & 0.6766981 & $Y=1.6338 X+-3.491$ & 1.573882 & $\begin{array}{l}2.02716 \\
1.22195\end{array}$ & 2.08 & \\
\hline Karanj oil & 1.7403561 & $Y=1.7596 X+-4.374$ & 2.125132 & $\begin{array}{l}2.65716 \\
1.69962 \\
\end{array}$ & 1.54 & \\
\hline Mahua oil & 1.63615455 & $Y=2.0370 X+-6.075$ & 2.734821 & $\begin{array}{l}3.42410 \\
2.18429\end{array}$ & 1.20 & \\
\hline Eucalyptus oil & 6.9783746 & $Y=1.9235 X+-5.610$ & 3.280003 & $\begin{array}{l}4.13731 \\
2.60033 \\
3.43778 \\
\end{array}$ & 1.00 & \\
\hline
\end{tabular}


The toxicity of different treatments was worked out by conducting bioassay against $3^{\text {rd }}$ instar larvae of $H$. armigera in laboratory by residue film method. The results obtained are presented in Table 2. The LC 50 value of Quinalphos, acephate, diflubenzuron, spinosad, b.t.k., neem oil, karanj oil, mahua oil and eucalyptus oil were 0.054005 , $0.227715, \quad 5.37584, \quad 1.025608, \quad 3.86555$, $1.573882,2.125132,2.73482$ and 3.28000 per cent, respectively. Quinalphos with LC 50 $(0.054005 \%)$ shows its superiority over the acephate with LC 50 of 0.227715 per cent against $H$.armigera. Among the bio-pesticides the LC 50 value of spinosad $(1.0256087 \%)$ which was lower than the b.t.k. (3.86555\%) and diflubenzuron $(5.37584 \%)$, so it was most effective as compared to other biopesticides. Among various plant products the $\mathrm{LC}_{50}$ value of neem oil (1.5738827\%) and eucalyptus oil $(3.2800034 \%)$ thus; neem oil shows its superiority over other plant products. So order of toxicity of different insecticides, biopesticides and plant products as under:

Insecticides: Quinalphos > Acephate

Bio-pesticides: Spinosad > B.t.k. > Difiubnzuron

Plant product: Neem oil > Karanj oil > Mahua oil > Eucalyptus oil

The toxicity, different treatments were divided into three categories viz., insecticides, bio-pesticides and plant products. The toxicity of different treatments was worked out in laboratory by bioassay method against third instar larvae of $H$. armigera. On the basis of LC 50 values against third instar larvae, the insecticides in descending order of toxicity were arranged as: insecticides: Quinalphos $(0.054005 \%)>$ acephate $(0.227715 \%)$, biopesticides: spinosad $(1.573882 \%)$, >b.t.k. $(3.86555 \%)>$ difubenzuron $(5.37584 \%)$ and Plant products: neem oil (1.573882) > karanj oil $(2.125132 \%)>$ mahua oil $(2.7348 \%)$ >eucalyptus oil $(3.28000 \%)$ (Table 2$)$. In the present investigation it was observed that Quinalphos was more toxic than acephate against third instar larvae of H.armigera. these finding are in conformity with earlier work of justin et al.,(1989). In present study the LC 50 value of B.t.k. was 3.86555 per cent under laboratory condition, it get support from the work of Reddy et al., (1997) who reported the effectiveness of B.t.k. against H.armigera and found that the medium lethal concentration $\mathrm{LC}_{50}$ value for B.t.k. against third instar larvae of $H$. armigera gave 90 per cent mortality. In present investigation on the basis of the LC ${ }_{50}$ value of different plant products, the eucalyptus oil was found to be less toxic as compared to other plant products. Jain and Gupta (1995) reported the effectiveness of insecticides, bio-pesticides and various plant products against H.armigera. The order of toxicity of different insecticides, biopesticides and plant products against larval instar of H.armigera was found as judo ( $\mathrm{LC}_{50}$ 0.001965-0.003376 per cent) >Dipel $\left(\mathrm{LC}_{50} 0.002498-0.0041113\right.$ per cent $)>$ decamethrin (LC 50 0.003064-0.004625 per cent) > NPV $\left(\mathrm{LC}_{50} 0.1078-0.2269\right)>$ neemax (LC 50 2.1032- 3.4745) > green commandos (LC ${ }_{50}$ 2.4945- 3.7489 per cent)

These finding are also in conformity with the finding of Kohja and Gupta (1992) who reported the LC 50 value of azadit 0.04518 0.05277 per cent against $H$. armigera. Bajpai and Sehgal (1998) observed 50 per cent mortality of neonate ( $24 \mathrm{hrs}$. old) larvae of H.armigera when semi- synthetic diets were treated with neem, karanj and tobacco formulations under laboratory conditions.

\section{References}

Abbott, W.S. (1925). A method of computing the effectiveness of an insecticides. $J$. Econ. Entomol. 18:265-267.

Anonymous. (1995). Technology for production of natural enemies. ICAR 
publication, pp. 75-78.

Bajpai, N.K. and Sehgal, V.K.(1998). Growth and development of Helicoverpa armigera neonate larvae on diets treated with neem, karanj and tobacco formulation. Abstract Published in National Seminar on Entomology in $21^{\text {st }}$ Century at RCA, Udaipur from April 30-May2, PP.136

Bhatt, N.J. and Patel, K.K. (2001) Biology and management of chickpea pod borer, Helicoverpa armigera (Hub.) Hardwick. Abstract published in national conference on "Plant protection -New Horizons in the Millennium" at RCA, Udaipur from Feb.23-25 Abstract No. 231, PP.70

Finney, D.J. (1971) Probit Analysis. The Cambridge University Press, Landon, P.333.

Jain, K.L. and Gupta, H.C.L. (1995).
Persistence and dissipation of residue of synthetic pyrethroids from okra fruits. Indian J.Appl.Ent. 10:15-18.

Justin, C.G.L., rabindra, R.J. and Jayraj, S. (1989). Increase insecticides in Helicoverpa armigera (Hub.) and Spodoptera litura larvae due to Bacillus thuringiensis Berliner treatment. Insect. Sci. Applic. 10(5):573-576.

Khoja, A.R. and Gupta, H.C.L. (1992) toxicity evaluation of natural and synthetic botanical against Helicoverpa armigera (Hub.). Indian J. Appl. Ent 6:27-31.

Reddy, G.R.S., Divakar, B.J. Reddy, S.M., Srivastava, H.P., Purohit, D.K. and Ram Reddy. (1997). Effect of two microbial bio-agents on the tomato borer, Helicoverpa armigera (Hub.) (Lepidoptera: Noctuidae). Microbial Biotechnology, 140-142.

\section{How to cite this article:}

Vipen Kumar, K.C. Gupta and Bagri, R.K. 2019. To Find out the Toxicity of Insecticides, BioPesticides and Plant Product against Helicoverpa armigera (Hubner) under Laboratory Conditions. Int.J.Curr.Microbiol.App.Sci. 8(01): 2896-2901. doi: https://doi.org/10.20546/ijcmas.2019.801.307 